\title{
The left inferior frontal gyrus is causally involved in selective semantic retrieval: Evidence from tDCS in primary progressive aphasia
}

Wang, Zeyi ${ }^{1}$, Ficek, Bronte $\mathrm{N}^{2}$, Webster, Kimberly $\mathrm{T}^{2,3}$, Onyike, Chiadi $\mathrm{U}^{4}$, Desmond, John $\mathrm{E}^{2,5}$, Hillis, Argye $\mathrm{E}^{2,6,7}$, Frangakis, Constantine $\mathrm{E}^{1,4,8}$, Caffo, Brian ${ }^{1}$ \& Tsapkini, Kyrana ${ }^{2,6}$

${ }^{1}$ Department of Biostatistics, Johns Hopkins School of Public Health, Baltimore, MD, USA

${ }^{2}$ Department of Neurology, Johns Hopkins Medicine, Baltimore, MD, USA

${ }^{3}$ Department of Otolaryngology - Head and Neck Surgery, Johns Hopkins Medicine, Baltimore, MD, USA

${ }^{4}$ Department of Psychiatry and Behavioral Sciences, Johns Hopkins Medicine, Baltimore, MD, USA

${ }^{5}$ Neuroscience Program, Johns Hopkins University, Baltimore, MD, USA

${ }^{6}$ Department of Cognitive Science, Johns Hopkins Medicine, Baltimore, MD, USA

${ }^{7}$ Department of Physical Medicine \& Rehabilitation, Johns Hopkins Medicine, Baltimore, MD, USA

${ }^{8}$ Department of Radiology, Johns Hopkins Medicine, Baltimore, MD, USA

\section{${ }^{*}$ Corresponding author:}

Kyrana Tsapkini, Ph.D.

Department of Neurology

600 N. Wolfe Street, Phipps 488

Baltimore, MD 21287, USA

Tel: +(1) 410-287-2464

Fax: +(1) 410-614-9807

Email: tsapkini@jhmi.edu 
medRxiv preprint doi: https://doi.org/10.1101/2020.07.20.20151043; this version posted July 26, 2020. The copyright holder for this preprint

(which was not certified by peer review) is the author/funder, who has granted medRxiv a license to display the preprint in perpetuity.

It is made available under a CC-BY-NC-ND 4.0 International license .

\begin{abstract}
Lesion and imaging studies have shown that the left inferior frontal gyrus (IFG) is involved in selective semantic retrieval of information from the temporal lobes. However, causal, i.e., interventional, evidence is sparse. In the present study we addressed this question by testing whether transcranial direct current stimulation (tDCS) over the left IFG in a group of individuals with primary progressive aphasia may improve semantic fluency, a task that relies to selective semantic retrieval. Semantic fluency improved significantly more in the tDCS vs. sham condition immediately post-treatment and improvement lasted up to 2 months. We further addressed the question of who will benefit most from such an intervention by testing possible demographic, clinical and functional connectivity variables that may predict the behavioral tDCS effect. We found that patients with stronger baseline functional connectivity between the subareas of the left IFG opercularis and triangularis, and between the middle temporal pole and superior temporal gyrus. were the most likely to benefit from tDCS over the left IFG. We thus provided causal evidence that the left IFG is the neural substrate of selective semantic retrieval and tDCS over the left IFG may improve semantic fluency in individuals with stronger baseline functional connectivity.
\end{abstract}

Key words: primary progressive aphasia, transcranial direct current stimulation, inferior frontal gyrus, semantic retrieval, verbal fluency, semantic fluency

Declarations of interest: none. 
medRxiv preprint doi: https://doi.org/10.1101/2020.07.20.20151043; this version posted July 26, 2020. The copyright holder for this preprint

(which was not certified by peer review) is the author/funder, who has granted medRxiv a license to display the preprint in perpetuity.

It is made available under a CC-BY-NC-ND 4.0 International license .

\section{Introduction}

Semantic fluency is a neuropsychological task in which a participant is asked to generate words that belong to specific semantic categories, such as fruits or animals (Lezak et al. 2004). The task of semantic fluency relies on the function of selective semantic retrieval. The distinction between function and task was at the heart of cognitive psychology and neuropsychology from the time of box diagrams (Caramazza 1997). Interestingly, from the early days of functional neuroimaging, it became evident that most brain areas, although they may specialize in certain functions (computations), are usually involved in several tasks (for a review, see Price, 2012). This understanding allows for the exciting possibility that if we were able to modulate the neural function of a particular area, then we would potentially modulate the cognitive function (computation) it performs and, consequently, several tasks that involve this function.

Functional magnetic resonance imaging (fMRI) studies in healthy controls have shown that selective semantic retrieval is regulated by the left inferior frontal gyrus (IFG) triangularis (Brodmann's area [BA] 45/47), which retrieves semantic information stored in the temporal brain regions (Binder \& Desai, 2011; Petrides, 2006; Rolheiser, Stamatakis, \& Tyler, 2011; Thompson-Schill, D’Esposito, Aguirre, \& Farah, 1997; Tyler et al., 2011). Further fMRI and diffusion tensor imaging (DTI) studies have shown that the left IFG triangularis is directly and monosynaptically connected to the temporal lobes via the extreme capsule fasciculus and that these pathways are critical for language comprehension (Frey et al. 2008; Saur, Kreher, Schnell, Kümmerer, Kellmeyer, Vry, Umarova, Musso, Glauche, Abel, et al. 2008; Rolheiser et al. 2011b). However, causal inference for the role of a particular brain area and a particular computation comes only from direct intervention studies targeting this area, such as in vivo electrical stimulation mostly during epilepsy surgery (see Rofes et al. 2018 for a review on language functions) or, more recently, neuromodulation studies such as transcranial direct current stimulation (tDCS).

Anodal tDCS is believed to induce long-term potentiation (LTP) in the stimulated brain region(s) by raising neuronal resting membrane potentials and thereby increasing excitability; however, the exact mechanisms are still an area of active research (Nitsche and Paulus 2000, 2011; Schlaug et al. 2011). TDCS has been shown to benefit language performance in post-stroke aphasia (Monti et al. 2008; Baker et al. 2010; Chrysikou and Hamilton 2011; Fiori et al. 2011; Fridriksson et al. 2011; Kang et al. 2011; Marangolo et al. 2011), and more recently as a potential adjunct to therapy in primary progressive aphasia (Mesulam, 2001, 2003, 2008), a neurodegenerative syndrome in which language abilities gradually deteriorate while other cognitive functions remain relatively intact in the early years of the condition (Cotelli et al. 2014; Tippett et al. 2015; Tsapkini et al. 2018). In the tDCS literature, many studies show transfer to untrained items/words. For example, in our recent clinical trial in 36 PPA participants we found variant effects in transfer to untrained items (Tsapkini et al. 2018; Cotelli et al. 2019). Few studies, however, evaluate generalization of tDCS effects to untrained tasks even if they subserve the same function: two in post-stroke aphasia (Marangolo et al. 2011; Meinzer et al. 2014) and 3 in PPA (Cotelli et al. 2014; Gervits et al. 2015; Roncero et al. 2017). From a clinical perspective, generalization of improvement is the most desirable outcome of an intervention approach, particularly because syndromes, such as PPA, often affect several language functions and performance deteriorates with time.

Given the small number of tDCS studies in PPA that show transfer effects to untrained tasks (only 3), we refer to each one separately. Cotelli and colleagues (2014) have shown that anodal tDCS over the left dorsolateral prefrontal cortex improved naming accuracy in 16 patients with non-fluent variant PPA (nfvPPA), and significant improvement was also found in self-assessments of speech production on functional communication scales (Cotelli et al. 2014). In another recent study, Gervits and colleagues found that six people with PPA, who narrated wordless children's books while undergoing 10 sessions of tDCS over the left frontal cortex (centered at F7), found significantly improved category (semantic) fluency compared to sham at follow-up intervals (Gervits et al. 2015). Roncero and colleagues (2017) also found transfer effects to untrained picture-naming items and digit span (forward and backward, [Wechsler 1981]) after tDCS over the left inferior parietal cortex in 10 patients with PPA (Roncero et al. 2017). 
medRxiv preprint doi: https://doi.org/10.1101/2020.07.20.20151043; this version posted July 26, 2020. The copyright holder for this preprint

(which was not certified by peer review) is the author/funder, who has granted medRxiv a license to display the preprint in perpetuity.

It is made available under a CC-BY-NC-ND 4.0 International license .

Therefore, there is encouraging preliminary evidence of transfer to other tasks, especially from Gervits and colleagues' study (i.e., transfer from a lexical retrieval task to semantic fluency). Furthermore, two additional studies directly targeted semantic fluency and found that a single session of tDCS over the left IFG improved semantic fluency in healthy controls showcasing its causal involvement in selective semantic retrieval (Cattaneo et al. 2011; Penolazzi et al. 2013).

Given the above evidence, we hypothesized that if the function of the left IFG (particularly the pars triangularis) is selective semantic retrieval of information stored in the temporal lobes (Thompson-Schill et al. 1997, 1999; Petrides 2006), then tDCS over the left IFG would also improve performance in other, non-trained tasks involving the function of active selective semantic retrieval, such as semantic fluency. In the present study, we used neuromodulation, a clinical intervention method, to address a neurocognitive question, i.e., whether the left IFG is causally involved in selective semantic retrieval, while at the same time addressing the important clinical question of treatment transfer to untrained tasks that rely on the same function (computation). The present study aimed to determine whether the tDCS effects in trained written-naming task can transfer to untrained semantic fluency tasks in a large cohort of patients with PPA - the largest PPA cohort, to our knowledge. Furthermore, in order to elucidate why transfer effects might occur and what are the characteristics of those individuals who may benefit from tDCS, we tested demographic, clinical and functional connectivity pairs as predictors of the semantic fluency modulation due to tDCS over the left IFG.

\section{Materials and Methods}

\subsection{Participants}

Thirty-six patients with PPA participated in this study (17 female): 14 with logopenic variant PPA (IvPPA), 13 with non-fluent variant PPA (nfvPPA), and 9 with semantic variant PPA (svPPA). All were right-handed, native English speakers, between 50 and 80 years old, and diagnosed based on clinical assessment, neuropsychological and language testing, and MRI, according to consensus criteria (GornoTempini et al. 2011). Informed consent was obtained from participants or their spouses, and all data were acquired in compliance with the Johns Hopkins Hospital Institutional Review Board. Figure 1 shows the participants recruited and their randomization to tDCS or sham condition. Each PPA variant group was matched by sex, age, education, years post onset of symptoms, overall FTD-CDR score and language severity measures (Tables $1 \mathrm{~A}, 1 \mathrm{~B})$. 
medRxiv preprint doi: https://doi.org/10.1101/2020.07.20.20151043; this version posted July 26, 2020. The copyright holder for this preprint (which was not certified by peer review) is the author/funder, who has granted medRxiv a license to display the preprint in perpetuity.

It is made available under a CC-BY-NC-ND 4.0 International license .

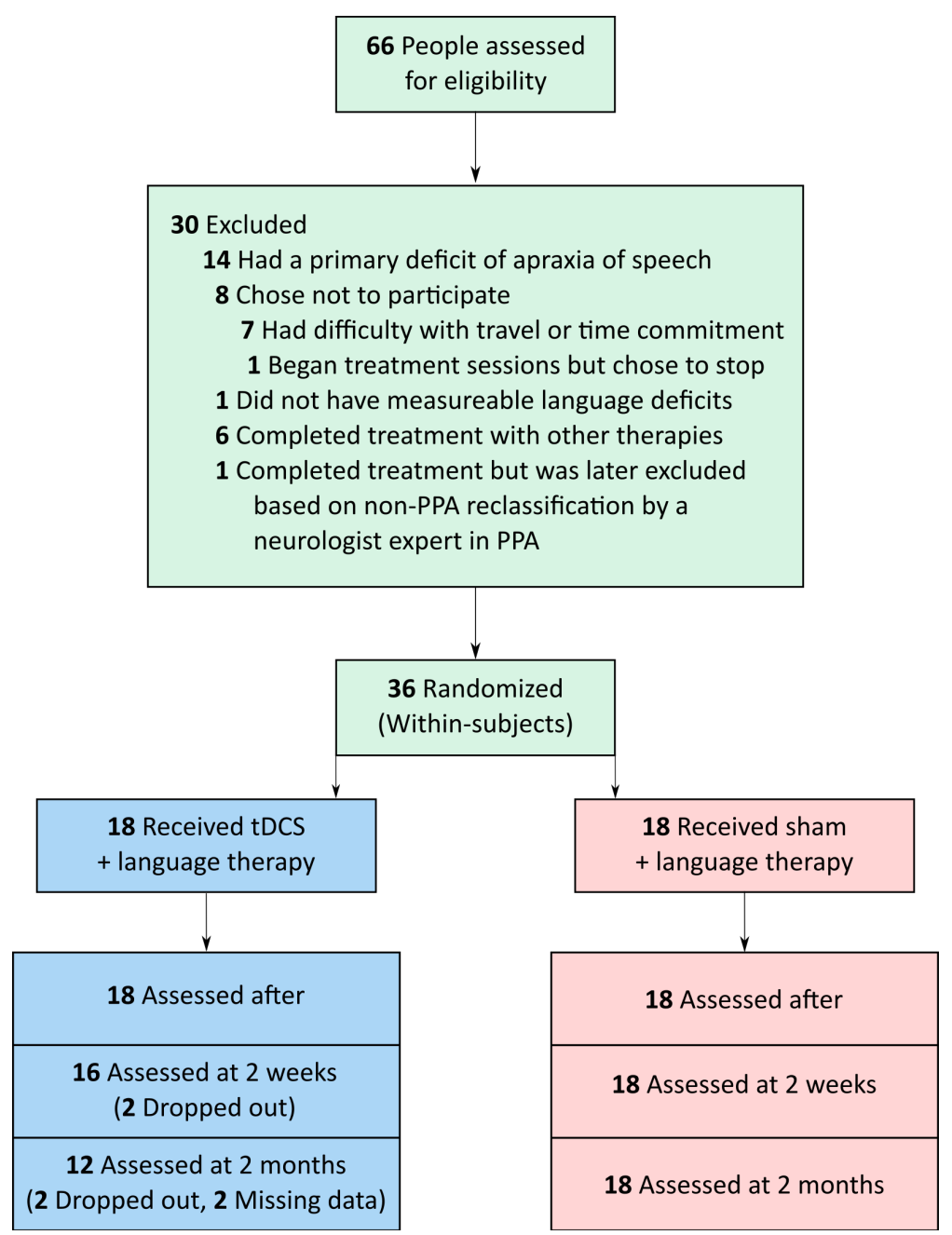

Figure 1. Participants recruited and randomization to tDCS or sham.

Table 1A. Means and standard deviations of demographic variables and baseline semantic fluency scores grouped by first-phase condition $(n=36)$. *Fisher's exact test used. FTD-CDR, Frontotemporal Dementia Clinical Dementia Rating Scale sum of boxes (Knopman et al. 2008). F, female; M, male. L, logopenic; N, nonfluent; S semantic.

\begin{tabular}{c|cccc}
\hline & tDCS first & sham first & $\mathrm{F}(1,34)$ & $\mathrm{p}$-value \\
\hline Sex & $9 \mathrm{~F}, 9 \mathrm{M}$ & $8 \mathrm{~F}, 10 \mathrm{M}$ & $*$ & 1.000 \\
Variant & $7 \mathrm{~L}, 6 \mathrm{~N}, 5 \mathrm{~S}$ & $7 \mathrm{~L}, 7 \mathrm{~N}, 4 \mathrm{~S}$ & ${ }^{*}$ & 0.500 \\
Age (years) & $66.17(7.49)$ & $69.72(5.42)$ & 2.66 & 0.113 \\
Years post symptom onset & $5.17(3.40)$ & $4.72(2.55)$ & 0.20 & 0.660 \\
Language severity (FTD-CDR) & $1.92(0.90)$ & $1.83(0.71)$ & 0.10 & 0.759 \\
Total severity (FTD-CDR) & $6.89(4.53)$ & $7.53(4.66)$ & 0.17 & 0.679 \\
Sessions in phase 1 & $12.72(2.11)$ & $11.06(1.63)$ & 7.05 & 0.012 \\
Baseline semantic fluency & $14.50(11.17)$ & $11.81(7.49)$ & 0.72 & 0.400 \\
\hline
\end{tabular}


medRxiv preprint doi: https://doi.org/10.1101/2020.07.20.20151043; this version posted July 26, 2020. The copyright holder for this preprint (which was not certified by peer review) is the author/funder, who has granted medRxiv a license to display the preprint in perpetuity. It is made available under a CC-BY-NC-ND 4.0 International license .

Table 1B. Means and standard deviations of demographic variables and baseline semantic fluency scores grouped by PPA variant $(n=36)$. *Fisher's exact test used. FTD-CDR, Frontotemporal Dementia Clinical Rating Scale sum of boxes (Knopman et al. 2008). F, female; M, male. s, sham; $t$, tDCS.

\begin{tabular}{c|ccccc}
\hline & IvPPA & nfvPPA & svPPA & F(2,33) & p-value \\
\hline Sex & $7 \mathrm{~F}, 7 \mathrm{M}$ & $5 \mathrm{~F}, 8 \mathrm{M}$ & $5 \mathrm{~F}, 4 \mathrm{M}$ & $*$ & 0.800 \\
First-phase condition & $7 \mathrm{~s}, 7 \mathrm{t}$ & $7 \mathrm{~s}, 6 \mathrm{t}$ & $4 \mathrm{~s}, 5 \mathrm{t}$ & $*$ & 1.000 \\
Age (years) & $66.29(8.11)$ & $69.77(6.00)$ & $67.89(4.96)$ & 0.91 & 0.412 \\
Years post symptom onset & $4.82(3.33)$ & $4.65(2.66)$ & $5.56(3.08)$ & 0.25 & 0.780 \\
Language severity (FTD-CDR) & $1.57(0.83)$ & $2.04(0.72)$ & $2.11(0.78)$ & 1.76 & 0.188 \\
Total FTD-CDR & $6.18(3.76)$ & $7.85(4.19)$ & $7.89(6.17)$ & 0.57 & 0.571 \\
Sessions in phase 1 & $11.93(2.02)$ & $11.85(1.91)$ & $11.89(2.47)$ & 0.01 & 0.990 \\
Baseline semantic fluency & $17.50(10.97)$ & $12.08(8.38)$ & $7.94(5.15)$ & 3.30 & 0.049 \\
\hline
\end{tabular}

\subsection{Overall design}

We used a within-subjects, double-blind, crossover design with two experimental conditions: speechlanguage therapy plus conventional anodal tDCS over the left IFG, and speech-language therapy plus sham tDCS. Each condition lasted approximately 12 consecutive weekday sessions; the two phases were separated by a 2-month wash-out period. Evaluations-consisting of a set of trained and untrained items of the same task, as well as extensive neuropsychological and neurolinguistic assessmentsoccurred immediately before, immediately after, two weeks after, and two months after each treatment phase. Participants, speech-language therapists, and examiners were blind to the experimental condition.

\section{3. tDCS methods}

Each daily therapy session lasted one hour. For both active tDCS and sham conditions, two $5 \mathrm{~cm} \times 5$ $\mathrm{cm}$, non-metallic, conductive, rubber electrodes covered with saline-soaked sponges were placed over the right cheek (cathodal electrode) and the left IFG centered at F7 of the EEG 10-20 electrode position (anodal electrode) (Homan 1988). The electrodes were hooked up to a Soterix 1x1 Clinical Trials device, which elicited a tingling sensation on the scalp as it ramped up within 30 seconds, to deliver current at an intensity of $2 \mathrm{~mA}$ (estimated current density $0.08 \mathrm{~mA} / \mathrm{cm}^{2}$; estimated total charge $0.096 \mathrm{C} / \mathrm{cm}^{2}$ ). In the tDCS condition, current was delivered for 20 minutes for a daily maximum of 2.4 Coulombs; in the sham condition, current ramped up to $2 \mathrm{~mA}$ over a $30 \mathrm{sec}$ interval and immediately ramped down to elicit the same tingling sensation, a procedure that has been shown to blind participants to treatment condition (cite Gandiga 2006 paper). Stimulation started at the beginning of each therapy session and lasted for 20 min whereas speech-language therapy continued for a full session, i.e., 25 additional minutes, for a total of 45-50 min of a regular speech-language therapy session. Twice during each session, participants rated their level of pain with the Wong-Baker FACES Pain Rating Scale (www.WongBakerFACES.org).

\subsection{Language intervention}

The language intervention protocol was based on studies that have successfully treated written language production. We adapted the basic design of a spell-study-spell procedure (Rapp and Glucroft 2009) to a lexical retrieval, oral and written naming paradigm (Beeson and Egnor 2006) to simultaneously target orthography, phonology and semantics. Although the intervention focused on written naming and spelling, this particular paradigm gave us the flexibility to accommodate the deficit in each variant (e.g., semantics in the svPPA, phonological paraphasias in IVPPA or apraxia of speech [AOS] errors in 
medRxiv preprint doi: https://doi.org/10.1101/2020.07.20.20151043; this version posted July 26, 2020. The copyright holder for this preprint

(which was not certified by peer review) is the author/funder, who has granted medRxiv a license to display the preprint in perpetuity.

It is made available under a CC-BY-NC-ND 4.0 International license .

nfvPPA). The exact steps are described in previous publications of the overall trial results (Tsapkini et al. 2018). To evaluate whether therapy gains generalized in other words, the words of the untrained set were presented at all evaluation points.

\subsection{Language and cognitive assessment: Verbal fluency}

Participants were also evaluated with a series of standardized language and cognitive assessments. For the semantic fluency task, participants were instructed to name as many fruits, animals, and vegetables as possible, administered separately in the order listed here, in one minute per category (Benton et al. 1994). Scores used in the present analysis were calculated by adding the number of words generated in all three categories. Performance was assessed before, immediately after, two weeks after, and two months after each phase.

\subsection{Imaging methods}

Of the 36 participants, 29 had magnetic resonance imaging (MRI) scans-five were severely claustrophobic and two had pacemakers and were therefore excluded. MRI scans took place at the Kennedy Krieger Institute at Johns Hopkins University. Magnetization-prepared rapid acquisition gradient echo (MPRAGE) and resting-state functional MRI (rsfMRI) scans were acquired before treatment on a 3Tesla Philips Achieva MRI scanner with a 32-channel head coil. T1-weighted MPRAGE sequence acquisition was performed according to the following parameters: a scan time of 6 minutes (150 slices); isotropic 1-mm voxel size; flip angle of $8^{\circ}$; SENSE acceleration factor of 2 ; TR/TE $=8 / 3.7$ milliseconds (ms). Resting-state fMRI acquisition was performed according to the following parameters: scan time of 9 minutes (210 time-point acquisitions); slice thickness of $3 \mathrm{~mm}$; in-plane resolution of $3.3 \times 3.3 \mathrm{~mm} 2$; flip angle of $75^{\circ}$; SENSE acceleration factor of 2; SPIR for fat suppression; TR/TE $=2500 / 30 \mathrm{~ms}$.

MPRAGE images were preprocessed and segmented into 283 regions of interest (ROIs) using MRICloud, a multi-atlas based, automated image parcellation approach. Preprocessing used a multiatlas fusion label algorithm (MALF) and large deformation diffeomorphic metric mapping (LDDMM) (Tang et al. 2013; Mori et al. 2016), a highly accurate diffeomorphic algorithm that minimizes effects of atrophy or local space deformations on mapping. All images were processed in native space. Volumes for each ROI were normalized by total intracerebral volume (brain tissue excluding myelencephalon and cerebrospinal fluid) to control for relative regional atrophy.

Resting-state fMRI scans were preprocessed using MRICloud and included standard routines from the SPM connectivity toolbox for coregistration, motion, and slice timing correction; physiological nuisance correction using CompCor (Behzadi et al. 2007); and motion and intensity TR outlier rejection using "ART" (https://www.nitrc.org/projects/artifact_detect/). To correct for motion, ART detected "outlier" TRs (2 standard deviations for motion and 4 standard deviations for intensity), which were used in combination with the physiological nuisance matrix in the deconvolution regression for the remaining TRs.

Resting-state fMRI scans were co-registered with MPRAGE scans into the same anatomical space (native space); then 78 of the ROls were parcellated on the rsfMRI scans. Average time courses for the voxels in each ROI were normalized, and correlations between ROI pairs were calculated and normalized with the Fisher z-transformation. Of the $78 \mathrm{ROIs}$, we chose the ones that comprise the language-network ROls and are connected to the left IFG, the stimulated area (excluding the angular gyrus since it also belongs to the default mode network) as well as the right homologue of the stimulated area (the left IFG) since it connects directly to it. We, thus, included all the 78 pairs of the following 13 ROls: the left and right pars opercularis, pars orbitalis, and pars triangularis of the inferior frontal gyrus (IFG_opercularis_L, IFG_opercularis_R, IFG_orbitalis_L, IFG_orbitalis_R, IFG_triangularis_L, IFG_triangularis_R), left midd̄le temporal gyrus (MTG_L), left supramarginal gyrus (SMG_L), left superior temporal gyrus (STG_L), left inferior temporal gyrus (ITG_L), left fusiform gyrus (FuG_L), pole of the left middle temporal gyrus (MTG_L_pole) and pole of the left superior temporal gyrus (STG_L_pole). 
medRxiv preprint doi: https://doi.org/10.1101/2020.07.20.20151043; this version posted July 26, 2020. The copyright holder for this preprint

(which was not certified by peer review) is the author/funder, who has granted medRxiv a license to display the preprint in perpetuity.

It is made available under a CC-BY-NC-ND 4.0 International license .

\subsection{Statistical analyses}

\subsubsection{Evaluation of $t D C S$ effects}

We evaluated the effect of tDCS immediately after, at two weeks, and at two months post the intervention using the first-phase data only, in order to rid the estimation of any possible impact of carryover effects. In fact, we focus on the first-phase data throughout the statistical analysis for a similar reason, to eliminate possible treatment-phase interaction due to possibly insufficient wash-out period.

The additional tDCS effect compared to sham was evaluated as the average treatment effect (ATE), $\delta_{(T \text { vs } S)}=E[Y \mid T=1]-E[Y \mid T=0]$, where $Y$ is the change in semantic fluency scores from baseline and $T$ is the treatment assignment indicator (valued as 1 for tDCS, 0 for sham). We assumed that $\left(Y_{i}, T_{i}\right), i=1$, $\ldots, n$, is an independent and identically distributed (IID) sample, and that the actual observed $Y_{i}$ is one of the two potential outcomes, $Y_{i}^{\top=1}$ and $Y_{i}{ }^{\top=0}$, depending on the treatment assignment, i.e. $Y_{i}=T_{i} Y_{i}{ }^{\top}=1+$ $\left(1-T_{i}\right) Y_{i}^{\top}=0$. These potential outcomes are defined as the changes would have been observed if the $i-$ th subject had been assigned to tDCS or sham, was observed. Treatment randomization guarantees that the preassigned treatment variable, $T_{i}$, is independent from the subsequent potential outcomes, $Y_{i}^{\top}=1$ and $Y_{i}{ }^{\top}=0$, and that the assignment probability is constant and positive. The following baseline covariates were used to improve the efficiency of statistical tests: baseline semantic fluency (Lazar et al. 2010; DeMarco and Turkeltaub 2018), PPA variant, number of treatment sessions, sex, age, years post onset of symptoms, and total FTD-CDR severity and language severity measures.

The estimation of ATE was conducted using the Targeted Minimum Loss-Based Estimation (TMLE) method (van der Laan and Rose 2011). We chose the method mainly for its advantage of flexibility in selecting the covariates automatically (based on cross validations), which reduced subjective modeling choices of the researchers. Meanwhile, TMLE achieves the desired properties as other commonly practiced methods. For example, TMLE guarantees the estimation consistency and asymptotic normality in randomized trials as analysis of covariances (ANCOVA) estimators, as well as the doubly robust local efficiency as augmented inverse propensity score weighting (AIPW) estimators. The TMLE R package (Gruber and Laan 2012) has been made available, which can be directly applied for the aforementioned ATE estimation problem. The estimator configuration details and the simulation evidence supporting the choice of method are provided in the supplementary materials (Appendix A). Estimations of the ATE are reported as the effect sizes (Glass et al. 1981) adjusted by the first-phase before-after sham group standard deviation $(S D=3.00)$. The standard errors, Z-test statistics, p-values, and $95 \%$ confidence intervals are reported.

To handle missing observations in semantic fluency due to dropouts at two weeks post (two dropouts) and two months post (six dropouts), we assumed Missing at Random (MAR), that is, given the knowledge of the observed semantic fluency values and the series of observed baseline covariates, whether a subject happened to drop out was assumed to have no impact on the unobserved semantic fluency values. TMLE can be applied to handle such missingness in the outcome (van der Laan and Rose 2011), and can be directly implemented with the TMLE R package (Gruber and Laan 2012).

\subsubsection{Variant effects}

Apart from the overall tDCS effect on semantic fluency and the functional connectivity pairs that predict it, we also investigated how it is modified by each variant subgroup at different time points. We assumed MAR and applied the linear mixed model (LMM) with random subject intercepts. In the fixed effect model, we included the following variables: the treatment assignment variable (tDCS and sham), the time point variable (after, 2 weeks and 2 months), as well as all the baseline covariates, were included as the main terms. Two-way interaction terms between time, treatment, and variant were added to the fixed effects. Three-way interaction terms were dropped in the final model, as none of these terms was significant with t-tests using Satterthwaite's degrees of freedom (Kuznetsova et al. 2017), and these terms did not significantly improve the model fitting either in the likelihood ratio test $\left(\chi^{2}(8)=5.40, p=\right.$ 0.714 ). Additional tDCS effects were evaluated at different time points (immediately after, two weeks post, and two months post) for each variant subgroup (nfvPPA, svPPA, IvPPA). Estimations of the effects 
medRxiv preprint doi: https://doi.org/10.1101/2020.07.20.20151043; this version posted July 26, 2020. The copyright holder for this preprint

(which was not certified by peer review) is the author/funder, who has granted medRxiv a license to display the preprint in perpetuity.

It is made available under a CC-BY-NC-ND 4.0 International license .

(adjusted by the first-phase before-after sham group standard deviation), standard errors, Wald test statistics, p-values and $95 \%$ confidence intervals were reported.

\subsubsection{Prediction of Potentially Heterogeneous tDCS effects from non-imaging factors and baseline rsfMRI}

We first investigated whether any of the non-imaging factors (baseline semantic fluency, PPA variant, number of treatment sessions, sex, age, years post onset of symptoms, and total FTD-CDR severity and language severity measures) was predictive of the individual tDCS effect. Secondly, we tested the imaging factors (correlations between the prespecified 13 language ROIs of the baseline rsfMRI; $78 \mathrm{ROI}$ pairs in total). For the second task, to handle missingness in the baseline resting-state functional connectivity data, an inverse propensity score weighting (IPW) method was applied. Propensity scores were estimated using logistic regression with the imaging missingness and baseline covariates. The inverse propensity scores were then used as weights; each least square fitting using all participants in the non-imaging predictor selection procedure was replaced with weighted linear regression on the complete cases. The selection criteria based on LOOCV predictive R-squared increase for predicting pseudovalues remained the same. Below we present the details of our methods.

For each participant, the individual-specific additional tDCS effect, $Y_{i}^{\top}=1-Y_{i}^{\top}=0$, which was defined as the difference between the potential change in semantic fluency had the participant been assigned to tDCS vs. had the individual been assigned to sham, may be heterogeneous. To evaluate which factors contributed to such inter-individual variability in the tDCS effect, we modeled them on the conditional average treatment effect (CATE), that is, $E\left[Y_{i}^{\top}{ }^{1}{ }^{-}-Y_{i}{ }^{\top}=0 \mid X_{i}\right]=E[Y \mid T=1, X]-E[Y \mid T=0, X]$, where $X$ represents a group of predictive factors. An immediate challenge was that each individual was assigned to one of the two treatment groups; therefore, only one of the two potential scenarios was observed. To handle this issue, a nonparametric regression method using jackknife pseudovalues was applied (Efron and Tibshirani 1994; Rubin and van der Laan 2007; Tian et al. 2014). The jackknife pseudovalue, $U_{i}$, of the $i$-th subject was calculated as a transformation of the observed behavioral outcome, $U_{i}=2 Y_{i} T_{i}-2 Y_{i}(1$ - $T_{i}$ ); such pseudovalue maintains the same conditional expectation structure as directly modeling the CATE, i.e. $E\left[U_{i} \mid X_{i}=x_{i}\right]=E\left[Y \mid T=1, X=x_{i}\right]-E\left[Y \mid T=0, X=x_{i}\right]$. Then the candidate factors were selected, depending on whether they were predictive to the resulted pseudovalues. Linearity was assumed and variable selection was conducted based on the leave-one-out cross validated (LOOCV) predictive R-squared. At each step of the forward selection, a threshold of $0.1(10 \%)$ on the R-squared increase was applied to stop the selection procedure, otherwise the variable with the largest R-squared increase was selected. The predictive R-squared and the root mean squared error (RMSE) of each step, as well as the increase in predictive R-squared compared to the previous step, are reported for each round of the variable selection in Figure 3.

\section{Results}

\section{1. tDCS tolerability}

Some participants reported tingling, itching, or discomfort from the stimulation, but no episodes of intolerability or adverse effects occurred. The maximum reported Wong-Baker FACES pain rating scale for each daily session was averaged across sessions and participants, with a tDCS mean pain rating of 2.21 (standard deviation 2.48, range $0-10$ ) and a sham mean rating of 2.14 (standard deviation 2.13, range $0-10)$.

\section{2. tDCS effects on spelling accuracy}

Previously, in the same patient cohort, we found that tDCS over the left IFG resulted in larger and longer-retained gains in letter accuracy for spelling trained items (words treated in therapy) and untrained items (words not treated in therapy as a measure of generalization to other items in the same task) as 
medRxiv preprint doi: https://doi.org/10.1101/2020.07.20.20151043; this version posted July 26, 2020. The copyright holder for this preprint

(which was not certified by peer review) is the author/funder, who has granted medRxiv a license to display the preprint in perpetuity.

It is made available under a CC-BY-NC-ND 4.0 International license .

compared to sham (Tsapkini et al. 2014, 2018). This additional improvement with tDCS was retained up to 2 months. We refer to the previous study only as background information here. In the present paper, we extend these findings to semantic fluency as a measure of treatment generalization.

\section{3. tDCS effects on semantic fluency}

We present the additional tDCS effects (over sham) immediately after, two weeks and two months post-intervention from the first phase of intervention only, to avoid possible carryover effects. Sematic fluency scores ranged from 0-46 words. Scores were generated by the sum of fruits, animals, and vegetables generated in one minute each. All statistical analyses were performed the changes from the baseline in the summed scores of the three semantic categories.

3.3.1. Evaluation of semantic fluency immediately after, two weeks post, and two months post the intervention

Restricting to the first-phase data, from before to after the intervention, the effect of tDCS vs. sham was significant, and the effect size was estimated as $1.35(95 \% \mathrm{Cl}[0.30,2.41]$, SE $=0.54, Z=2.52, p=$ 0.012) adjusted for all the following covariates (baseline semantic fluency, PPA variant, number of treatment sessions, sex, age, years post onset of symptoms, and total FTD-CDR severity and language severity measures) as listed in Section 2.7.1. Thus, tDCS showed an additional effect that is 1.35 times the standard deviation of the sham group's change $(S D=3)$ in the semantic fluency score.

Significant tDCS effect on semantic fluency was also confirmed two weeks post the intervention (effect size estimation 1.56, 95\% Cl: [0.40, 2.73], SE: $0.59, Z=2.64, p=0.008$ ) but not two months post the intervention (effect size estimation 1.08, 95\% Cl: [-0.17, 2.33], SE: $0.64, Z=1.69, p=0.091$ ).

\subsubsection{Variant effects}

People with nfvPPA appeared to show the greatest generalization of improvement to semantic fluency, with the largest (compared to other variants) effect sizes at all 3 follow-up points: immediately after (estimated as 1.72), at two weeks post (1.71), and at two months post treatment (1.48). See Table 2. The effect size of tDCS in IvPPA was smaller than in nfvPPA immediately after (1.07), and at two weeks post (1.06) but diminished at two months post (0.83). The effect size of tDCS in svPPA was the smallest amongst variants at any follow-up point $(0.55,0.54$ and 0.31 , immediately after, at two weeks post and at two months post, respectively). 
medRxiv preprint doi: https://doi.org/10.1101/2020.07.20.20151043; this version posted July 26, 2020. The copyright holder for this preprint (which was not certified by peer review) is the author/funder, who has granted medRxiv a license to display the preprint in perpetuity.

It is made available under a CC-BY-NC-ND 4.0 International license .

Table 2. Effect sizes for improvement in semantic fluency across variants immediately after, two weeks post, and two months post the intervention. The first phase data was used. Estimations were for the effect sizes divided by phase 1 before-after sham group standard deviation ( $S D=3.00)$, adjusting for the baseline covariates as listed in Section 2.7.1.

\begin{tabular}{lllllll}
\hline & Estimate & SE & $\chi^{2}(1)$ & $p$ & Lower & Upper \\
T vs S, nfvPPA, After & 1.72 & 0.58 & 8.71 & 0.003 & 0.58 & 2.86 \\
T vs S, IvPPA, After & 1.07 & 0.56 & 3.60 & 0.058 & -0.04 & 2.18 \\
T vs S, svPPA, After & 0.55 & 0.71 & 0.60 & 0.437 & -0.84 & 1.93 \\
T vs S, nfvPPA, 2week & 1.71 & 0.58 & 8.63 & 0.003 & 0.57 & 2.85 \\
T vs S, IvPPA, 2week & 1.06 & 0.58 & 3.31 & 0.069 & -0.08 & 2.20 \\
T vs S, svPPA, 2week & 0.54 & 0.70 & 0.59 & 0.442 & -0.84 & 1.91 \\
T vs S, nfvPPA, 2month & 1.48 & 0.62 & 5.62 & 0.018 & 0.26 & 2.70 \\
T vs S, IvPPA, 2month & 0.83 & 0.62 & 1.81 & 0.178 & -0.38 & 2.04 \\
T vs S, svPPA, 2month & 0.31 & 0.72 & 0.18 & 0.670 & -1.10 & 1.71 \\
\hline
\end{tabular}

3.3.3. Prediction of Potentially Heterogeneous tDCS effects: non-imaging factors

We tested the following non-imaging factors for predicting the additional tDCS effect on semantic fluency: baseline semantic fluency, PPA variant, number of treatment sessions, sex, age, years post onset of symptoms, and dementia and language severity (Frontotemporal Dementia Clinical Dementia Rating [FTD-CDR] overall sum and language measure, respectively) (Knopman et al. 2008) as we explain in the Statistical Analysis section (2.7.3). None of the non-imaging factors predicted the individual tDCS effect with R-squared increment thresholded at $0.1(10 \%)$. However, dementia severity (overall FTD-CDR sum) and belonging to the nfvPPA group marginally predicted the additional tDCS effect in semantic fluency. Each provided $4.4 \%$ and $5.4 \%$ increases, respectively, in predictive R-squared and resulted in an accumulated R-squared of $9.8 \%$ (see Table 3 ).

Table 3. Non-imaging factors for individual tDCS effect prediction.

\begin{tabular}{llll}
\hline & Accumulated $\mathrm{R}^{2}$ & $\mathrm{R}^{2}$ increase & RMSE \\
\hline Null Model & 0 & 0 & 8.360 \\
Overall FTD-CDR & 0.044 & 0.044 & 8.407 \\
Having nfvPPA & 0.098 & 0.054 & 8.166 \\
\hline
\end{tabular}


medRxiv preprint doi: https://doi.org/10.1101/2020.07.20.20151043; this version posted July 26, 2020. The copyright holder for this preprint (which was not certified by peer review) is the author/funder, who has granted medRxiv a license to display the preprint in perpetuity. It is made available under a CC-BY-NC-ND 4.0 International license .

\subsubsection{Prediction of Potentially Heterogeneous tDCS effects: imaging factors}

We tested a total of 78 resting-state functional connectivity pairs from 13 language network regionsof-interest (ROIs) as predictors for the additional tDCS effect on semantic fluency by taking into account statistically the individual heterogeneity of the participants. The whole analysis procedure is described in detail in Section 2.7.3. Since we had not found any single demographic or clinical factor to predict the additional tDCS effect above the R-squared minimum threshold of $10 \%$ (see above section 3.3.3), we did not enter any other factors in the regression model to save degrees of freedom given the sample size. Admittedly, the trade-off could be that the prediction effect would possibly be confounded by other baseline non-imaging factors. However, the comparison between the final models from the non-imaging and imaging predictors (Tables 3 and 4 ) in terms of the accumulated predictive $R^{2}(0.098$ vs 0.446$)$ and the RMSE (8.166 vs 6.431) indicated that the imaging predictors outweighed the non-imaging ones in predictive value. Furthermore, the selected imaging factors are not significantly different in the three variant groups (Left STG : Left MTG pole, $F(2,21)=0.13, p=0.88$; Left IFG opercularis : Left IFG triangularis, $F(2,21)=0.76, p=0.48$; assuming missing completely at random) and are not significantly associated with Overall FTD-CDR (Left STG : Left MTG pole, Estimate $=8.58 \mathrm{E}-4, \mathrm{SD}=8.45 \mathrm{E}-3, \mathrm{t}(22)=$ $0.10, p=0.92$; Left IFG opercularis : Left IFG triangularis, Estimate $=-1.00 \mathrm{E}-2, \mathrm{SD}=1.37 \mathrm{E}-2, \mathrm{t}(22)=-$ $0.73, p=0.47$; assuming missing completely at random); thus it was confirmed that their predictiveness for tDCS effects was not merely due to potential association with variant differences or dementia severity.

Two baseline resting-state functional connectivity ROI pairs predicted the additional tDCS effect on semantic fluency above $10 \%$ of R-squared increase $(0.1$ threshold): (1) the left superior temporal gyrus (STG)-to-left medial temporal gyrus (MTG) pole and, (2) left IFG opercularis-to-left IFG triangularis (Table 4; Figure 2). The cumulative predictive R-squared of these two pairs was 0.446 , i.e., $44.6 \%$ (RMSE=6.64). This result was confirmed in the refitted linear prediction model. Coefficients of this model were shown in Table 5. Higher baseline connectivity in these pairs was associated with higher additional tDCS effect. In addition, we monitored the changes of $\mathrm{R}^{2}$ increases in each round of variable selection (Figure 3 ). Note that in the first round three other imaging predictors provided $\mathrm{R}$-squared increases greater than 0.1 , but they were not selected because the Left STG: Left MTG pole had been selected for providing a larger Rsquared increase.

Table 4. Imaging factors that predicted the individual tDCS effect. Predictiveness was evaluated by the LOOCV (predictive) $\mathrm{R}^{2}$.

\begin{tabular}{llll}
\hline & Accumulated $\mathrm{R}^{2}$ & $\mathrm{R}^{2}$ increase & RMSE \\
\hline Null Model & 0 & 0 & 8.534 \\
Left STG : Left MTG pole & 0.340 & 0.340 & 7.250 \\
Left IFG opercularis : Left IFG triangularis & 0.446 & 0.106 & 6.641 \\
\hline
\end{tabular}

Table 5. The prediction model for individual tDCS effects with the two selected imaging factors.

\begin{tabular}{lllll}
\hline & Estimate & SE & $t(21)$ & $P$ \\
\hline Intercept & -11.38 & 3.59 & -3.17 & 0.005 \\
Left STG : Left MTG pole & 33.60 & 7.11 & 4.72 & 0.000 \\
Left IFG opercularis : Left IFG triangularis & 13.59 & 4.79 & 2.84 & 0.010 \\
\hline
\end{tabular}


medRxiv preprint doi: https://doi.org/10.1101/2020.07.20.20151043; this version posted July 26, 2020. The copyright holder for this preprint (which was not certified by peer review) is the author/funder, who has granted medRxiv a license to display the preprint in perpetuity.

It is made available under a CC-BY-NC-ND 4.0 International license .

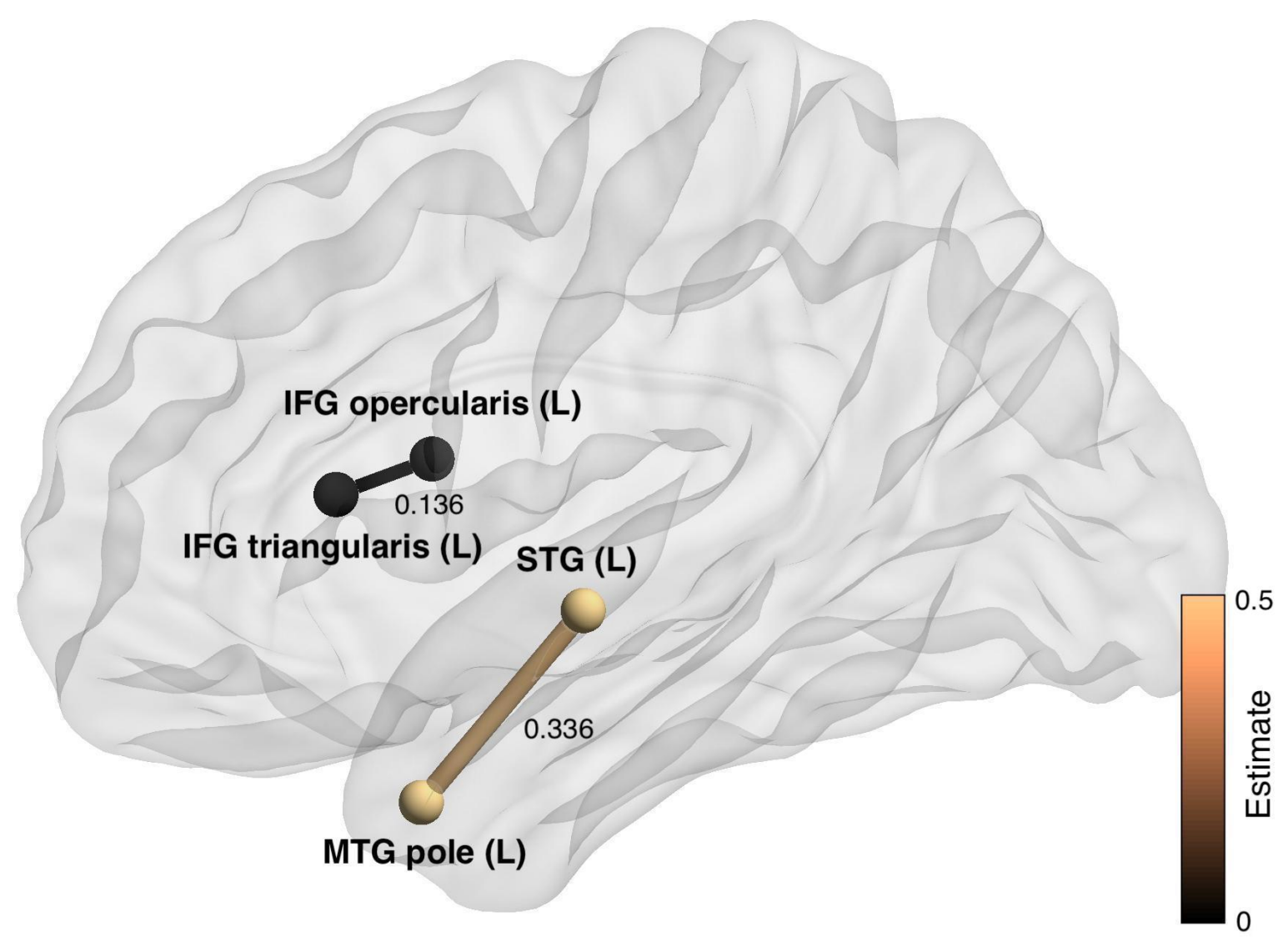

Figure 2. Visualization of the selected predictive imaging pairs for the additional tDCS effects. The positions of the nodes represent the average centers of each ROI from the cohort, rather than actual spatial distance. ROI pairs are plotted and connected if predictiveness of the baseline connectivity is confirmed. Thickness of the edge and the scale of the edge color represent on average how much additional semantic fluency increase one would expect for tDCS compared to sham, with 0.01 higher baseline Fisher z-transformed connectivity. 
medRxiv preprint doi: https://doi.org/10.1101/2020.07.20.20151043; this version posted July 26, 2020. The copyright holder for this preprint (which was not certified by peer review) is the author/funder, who has granted medRxiv a license to display the preprint in perpetuity.

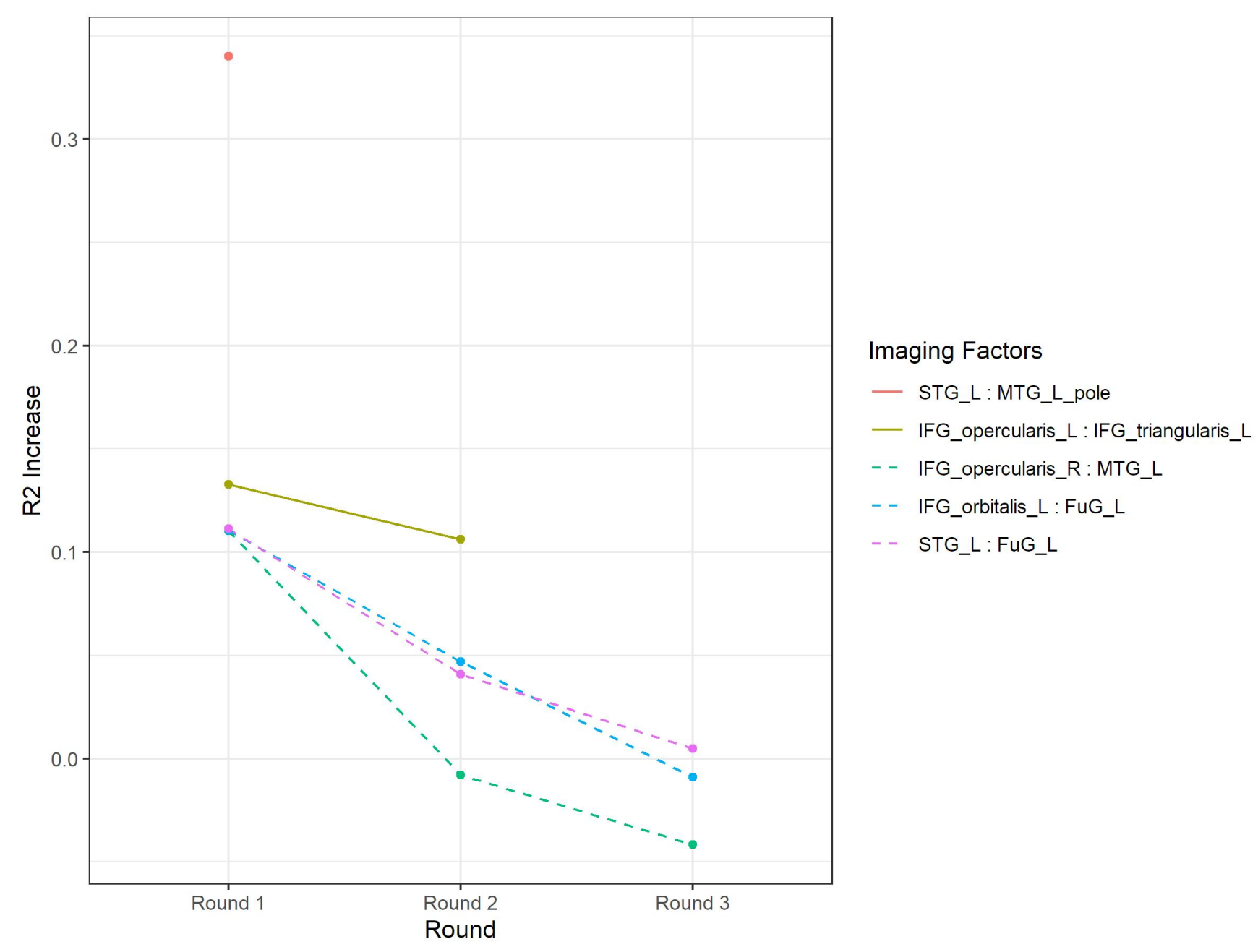

Figure 3. Functional connectivity pairs predicting the increases in R-squared for the individual tDCS effects. Solid lines represent the selected factors in each round of the regression, whereas dotted lines represent the factors that were not selected but also provided over 0.1 increase of predictive R-squared in the first round.

\section{Discussion}

In the present study we evaluated the effects of anodal tDCS over left IFG (vs sham) on semantic fluency to provide causal evidence on the role of the left IFG in selective semantic retrieval. Previously, we (Tsapkini et al. 2018) and others (Cotelli et al. 2014; McConathey et al. 2017; Roncero et al. 2017) found positive effects of tDCS in PPA, especially in lexical retrieval tasks, such as oral and written naming following tDCS over the left IFG (Tsapkini et al. 2018). Given these results, we hypothesized that if the left IFG (triangularis, BA 45) subserves the function of selective semantic retrieval (Petrides 1995, 2014), particularly in selecting some aspect or subset of available information among competing alternatives (Thompson-Schill et al. 1997, 2005), then tDCS over this area will improve performance on a task of semantic selection, such as semantic verbal fluency, even if not explicitly trained. Given that selective semantic retrieval depends on functional (and likely structural) connections between the left IFG and temporal cortices (Tyler et al. 2011a; Margulies and Petrides 2013; Petrides 2014), we also hypothesized that baseline functional connectivity of these areas will predict the tDCS effect in semantic fluency. From 
medRxiv preprint doi: https://doi.org/10.1101/2020.07.20.20151043; this version posted July 26, 2020. The copyright holder for this preprint

(which was not certified by peer review) is the author/funder, who has granted medRxiv a license to display the preprint in perpetuity.

It is made available under a CC-BY-NC-ND 4.0 International license .

a clinical perspective, we also examined the role of baseline functional connectivity between the stimulated area (left IFG) and its functionally connected areas as a biomarker for who would benefit more from tDCS. We found that performance in semantic fluency improved significantly more in the tDCS condition than in sham. The additional improvement was maintained up to two months post-treatment. In a subsequent analysis of which PPA variant may benefit more from tDCS, we found that this effect was stronger in nfvPPA. Resting-state functional connectivity between semantic representation areas and semantic control areas predicted the tDCS effect on semantic fluency: (1) the left MTG pole to left STG and (2) the left IFG pars opercularis to pars triangularis. Furthermore, higher baseline functional connectivity between the adjacent areas in these two pairs predicted larger increases in semantic fluency. Importantly, the effects were specific to selective semantic retrieval. In other words, there were no effects of tDCS on other cognitive tasks that do not depend on the left IFG, including digit span forward (on AfterBefore changes, $95 \% \mathrm{Cl}[-0.28,0.89]$, Estimate $=0.31, \mathrm{SE}=0.29, t(34)=1.06, p=0.290)$ and Trail $\mathrm{A}$ (Tombaugh 2004) (on After-Before changes, 95\% Cl [-19.14, 28.89], Estimate $=4.87$, SE $=11.19, t(14)$ $=0.44, p=0.670$ ), nor was there a tDCS effect of any index of general improvement, such as the Patient Health Questionnaire -9 [PHQ-9] (Kroenke et al. 2001) (on After-Before changes, 95\% Cl [-2.41, 5.41], Estimate $=1.50, \mathrm{SE}=1.82, t(14)=0.82, p=0.424)$. These findings demonstrate the specificity of positive far-transfer effects of tDCS to a non-trained task the depends on the left IFG, in the largest cohort of people with a neurodegenerative syndrome, PPA, to date. The present study significantly informs our neurocognitive understanding of the causal role of the left IFG in selective semantic retrieval, while also demonstrating important clinical implications on which patients will improve from tDCS over the left IFG.

The present study aligns with other tDCS studies in healthy aging and post-stroke aphasia that found tDCS to facilitate transfer of therapy effects to untrained tasks. For example, Marangolo et al. (2011) report that oral naming improved in post-stroke aphasia following apraxia of speech (AOS) training in conjunction with tDCS over the left IFG (Marangolo et al. 2011), and Meinzer et al. (2014) report that oral naming improved in mild cognitive impairment $(\mathrm{MCl})$ after stimulation over the left motor cortex (M1)(Meinzer et al. 2014). With regard to tDCS studies in PPA, our study aligns with previous tDCS transfer effects on verbal fluency in smaller studies that targeted a variety of other language functions and tasks (Gervits et al. 2015; Roncero et al. 2017; Hosseini et al. 2019) ranging from generic tasks such as story-telling (Gervits et al. 2015) to oral naming (Roncero et al. 2017; Hosseini et al. 2019). The present study, thus, confirms in a large group of patients with adequate power that stimulation over the left IFG improves selective semantic retrieval even if not explicitly trained.

Another important finding in the present study is that the strength of functional connectivity between adjacent areas in both semantic processing areas (MTG and STG), as well as semantic control areas (IFG opercularis and triangularis), predicted the magnitude of tDCS effect on semantic fluency. This seems to be at odds with the atrophy in frontal areas, especially in nfvPPA who showed the largest tDCS effect. Given that we (Tao et al. under review) and others (Agosta et al. 2013; Mandelli et al. 2016) have not found a correlation between functional connectivity and atrophy, we would like to entertain the following possible hypotheses for the present results. (1) tDCS may be more beneficial on atrophied (but still viable) tissue, enhancing its lower baseline function. (2) Alternatively, tDCS may work better when other network or compensatory brain areas remain intact. People with nfvPPA, for example, have nonatrophied temporal regions (Gorno-Tempini et al., 2011). If functional connectivity within temporal regions best predicts the tDCS effects, perhaps their functioning, important for semantic storage and organization, compensates for frontal dysfunction and facilitates semantic retrieval. (3) Another possible hypothesis could be what we call 'functional diaschisis', i.e., compensatory brain regions (other IFG subregion or the right IFG) may mediate the response of the left IFG to tDCS. Despite the fact we have not found strong evidence for this hypothesis in the present study, the functional connectivity pairs in the different rounds of regression (shown in Figure 3) provide suggestions for the role of the right IFG and other temporal areas. 
medRxiv preprint doi: https://doi.org/10.1101/2020.07.20.20151043; this version posted July 26, 2020. The copyright holder for this preprint

(which was not certified by peer review) is the author/funder, who has granted medRxiv a license to display the preprint in perpetuity.

It is made available under a CC-BY-NC-ND 4.0 International license .

Lesion studies have shown that the neural substrates of semantic fluency are the left (or bilateral) IFG (particularly the IFG pars triangularis) and temporal areas, such as the MTG and ITG. More specifically, lesion studies have shown that the left temporal cortex stores information about semantic categories, and frontal areas are important in accessing this information (Mummery et al. 1999; Baldo et al. 2006). We also found that left ITG is associated with storage of lexical characteristics of both nouns and verbs in PPA (Race et al. 2013; Riello et al. 2018). With regard to verbal fluency in PPA, a previous study (Libon et al. 2009), as well as a recent one from our group (Riello et al. under review) where we controlled for dementia severity, found that atrophy in the anterior and inferior left temporal regions and right frontal regions were associated with semantic fluency.

Functional neuroimaging studies have provided strong evidence for the role of the left IFG in selective semantic retrieval from temporal areas (Thompson-Schill et al. 1997; Petrides 2006; Binder and Desai 2011; Rolheiser et al. 2011a; Tyler et al. 2011a). In a systematic review of fMRI studies related to semantic fluency, Costafreda and colleagues (2006) supported the association between semantic fluency and brain activation (BOLD signal) in the anterior and ventral portions of the left IFG (Costafreda et al. 2006). Thompson-Schill and colleagues argued that the left IFG triangularis is important for the selection of some aspect or subset of available information among competing alternatives, e.g., semantic category (Thompson-Schill, Aguirre, D'Esposito, \& Farah, 1999; Thompson-Schill et al., 1997). Many studies have implicated the left IFG in strategic lexical retrieval pointing to the differential roles of the subdivided left IFG: the pars opercularis (BA 44) for phonologically-cued implicated retrieval and the pars triangularis (BA 45) for strategic semantically-cued retrieval (implicating BA 45) (Katzev et al. 2013; Petrides 2014). In particular, Amunts and colleagues (Amunts et al. 1999, 2004; Gurd et al. 2002) combining evidence from $\mathrm{fMRI}$ and cytoarchitectonic mapping, showed that although both BA 44 and BA 45 participate in verbal fluency, they do so differently: BA 44 is most likely involved in high-level programming of speech production, while BA 45 is more involved in semantic aspects of language processing (Grodzinsky and Amunts 2006). The present study adds causal evidence from tDCS for the role of the left IFG in selective semantic retrieval of verbal information stored in long-term memory in the temporal lobe (Petrides 1995; Thompson-Schill et al. 1997, 2005).

Interestingly, in the present study the two most significant functional connectivity pairs that predicted the tDCS effect on semantic fluency correspond to areas at the edges of the extreme capsule fasciculus, a white-matter bundle connecting the left IFG triangularis to temporal areas as part of the ventral language stream (Hickok and Poeppel 2007; Saur, Kreher, Schnell, Kümmerer, Kellmeyer, Vry, Umarova, Musso, Glauche, Abel, et al. 2008; Friederici 2009). Recent tractography studies using sensitive DTI in humans have traced this fasciculus (Frey et al. 2008) and demonstrated how it connects the IFG with anterior temporal and superior temporal regions. Furthermore, several studies have shown that the extreme capsule is important for semantic processing and comprehension (Saur, Kreher, Schnell, Kümmerer, Kellmeyer, Vry, Umarova, Musso, Glauche, and Abel 2008; Friederici 2009; Tyler et al. 2011b). Although this bundle is sometimes hard to detect and many times considered as part of the uncinate, in vivo tracing studies in humans and the macaque have shown that the uncinate connects prefrontal regions to anterior temporal and involves emotional regulation (Petrides and Pandya 2009). The structural white matter connections between semantic control (the left IFG) and semantic processing areas (the anterior, inferior, and middle temporal and fusiform gyri) may allow the left IFG to act as the neural substrate of selective retrieval of categorical information stored in temporal areas. In a recent study, we have also identified the white-matter integrity of this bundle as a significant predictor of tDCS but not language therapy alone (sham) for trained words during written naming therapy (Zhao et al. under review). However, in that study the contribution of the structural connectivity to the tDCS effect was much more modest $(12 \%)$ than here $(46 \%)$ showing that functional connectivity is a better predictor of the tDCS effects in PPA. 
medRxiv preprint doi: https://doi.org/10.1101/2020.07.20.20151043; this version posted July 26, 2020. The copyright holder for this preprint

(which was not certified by peer review) is the author/funder, who has granted medRxiv a license to display the preprint in perpetuity.

It is made available under a CC-BY-NC-ND 4.0 International license .

Functional connectivity has also been identified as a mechanism of tDCS effects in previous studies by Meinzer and colleagues for healthy aging (Meinzer et al. 2012, 2013) and MCl (Meinzer et al. 2014), as well as by our group for PPA (Ficek et al. 2018). These studies identified decreases of functional connectivity between long-distance areas belonging to the same network (between the stimulated left IFG and temporal areas) as a tDCS mechanism. How do these previous decreases between distal areas as a tDCS mechanism reconcile with the present increases in correlation between adjacent areas as a predictor for tDCS effects? Previous studies in neurodegenerative disorders, including AD (Dickerson et al. 2005; Bakker et al. 2012) and PPA (Tao et al. under review; Mandelli et al. 2016), have identified increases of functional connectivity in areas that are at risk of atrophy and are subsequently lost as functional hubs. These increases have been interpreted as manifestations of a probable compensatory mechanism (Dickerson et al. 2005; Meinzer et al. 2012, 2014) or as manifestations of the disease progression itself since they did not always correspond to sustained performance (Bakker et al. 2012). Meinzer and colleagues (2013) suggested that tDCS downregulates that hyperactivity or hyperconnectivity (Meinzer et al. 2013), and our previous findings converged to this suggestion (Ficek et al. 2018).

The present tDCS study provides causal evidence that the left IFG is a critical area for selective semantic retrieval even in neurodegenerative conditions such as PPA. Furthermore, stronger functional connectivity within semantic processing and semantic control areas predict better performance in a selective semantic retrieval task (semantic fluency). The results of the present study have also important clinical implications, indicating that nfvPPA may benefit more from tDCS over the left IFG. Furthermore, baseline functional connectivity in semantic processing and semantic control areas may be biomarkers for selecting patients who will benefit more from tDCS. Further work confirming mechanisms by which tDCS may affect functional connectivity or be influenced by fronto-temporal structural or functional connectivity is warranted.

\section{Acknowledgements}

We would like to thank our participants and referring physicians for their dedication and interest in our study. Funding: This work was supported by grants from the Science of Learning Institute at Johns Hopkins University and by the National Institutes of Health (National Institute of Deafness and Communication Disorders) through award R01 DC014475 to KT. AH was supported by NIH (NIDCD) through awards R01 DC03681, R01 DC011317 and P50 DC014664.

\section{References}

Agosta F, Galantucci S, Canu E, Cappa SF, Magnani G, Franceschi M, Falini A, Comi G, Filippi M. 2013. Disruption of structural connectivity along the dorsal and ventral language pathways in patients with nonfluent and semantic variant primary progressive aphasia: a DT MRI study and a literature review. Brain Lang. 127:157-166.

Amunts K, Schleicher A, Bürgel U, Mohlberg H, Uylings HB, Zilles K. 1999. Broca's region revisited: cytoarchitecture and intersubject variability. J Comp Neurol. 412:319-341.

Amunts K, Weiss PH, Mohlberg H, Pieperhoff P, Eickhoff S, Gurd JM, Marshall JC, Shah NJ, Fink GR, Zilles K. 2004. Analysis of neural mechanisms underlying verbal fluency in cytoarchitectonically defined stereotaxic space-The roles of Brodmann areas 44 and 45. Neurolmage. 22:42-56. 
medRxiv preprint doi: https://doi.org/10.1101/2020.07.20.20151043; this version posted July 26, 2020. The copyright holder for this preprint (which was not certified by peer review) is the author/funder, who has granted medRxiv a license to display the preprint in perpetuity. It is made available under a CC-BY-NC-ND 4.0 International license .

Baker JM, Rorden C, Fridriksson J. 2010. Using transcranial direct-current stimulation to treat stroke patients with aphasia. Stroke J Cereb Circ. 41:1229-1236.

Bakker A, Krauss GL, Albert MS, Speck CL, Jones LR, Stark CE, Yassa MA, Bassett SS, Shelton AL, Gallagher M. 2012. Reduction of hippocampal hyperactivity improves cognition in amnestic mild cognitive impairment. Neuron. 74:467-474.

Baldo JV, Schwartz S, Wilkins D, Dronkers NF. 2006. Role of frontal versus temporal cortex in verbal fluency as revealed by voxel-based lesion symptom mapping. J Int Neuropsychol Soc. 12:896900.

Beeson PM, Egnor H. 2006. Combining treatment for written and spoken naming. J Int Neuropsychol Soc JINS. 12:816-827.

Behzadi Y, Restom K, Liau J, Liu TT. 2007. A component based noise correction method (CompCor) for BOLD and perfusion based fMRI. Neuroimage. 37:90-101.

Benton AL, Sivan AB, deS Hamsher K, Spreen O. 1994. Contributions to neuropsychological assessment: A clinical manual. Oxford University Press, USA.

Binder JR, Desai RH. 2011. The neurobiology of semantic memory. Trends Cogn Sci. 15:527-536.

Caramazza A. 1997. How many levels of processing are there in lexical access? Cogn Neuropsychol. 14:177-208.

Cattaneo Z, Pisoni A, Papagno C. 2011. Transcranial direct current stimulation over Broca's region improves phonemic and semantic fluency in healthy individuals. Neuroscience. 183:64-70.

Chrysikou EG, Hamilton RH. 2011. Noninvasive brain stimulation in the treatment of aphasia: Exploring interhemispheric relationships and their implications for neurorehabilitation. Restor Neurol Neurosci.

Costafreda SG, Fu CHY, Lee L, Everitt B, Brammer MJ, David AS. 2006. A systematic review and quantitative appraisal of fMRI studies of verbal fluency: Role of the left inferior frontal gyrus. Hum Brain Mapp. 27:799-810.

Cotelli M, Manenti R, Ferrari C, Gobbi E, Macis A, Cappa SF. 2019. Effectiveness of language training and non-invasive brain stimulation on oral and written naming performance in Primary Progressive Aphasia: A meta-analysis and systematic review. Neurosci Biobehav Rev.

Cotelli M, Manenti R, Petesi M, Brambilla M, Cosseddu M, Zanetti O, Miniussi C, Padovani A, Borroni B. 2014. Treatment of primary progressive aphasias by transcranial direct current stimulation combined with language training. J Alzheimers Dis JAD. 39:799-808.

DeMarco AT, Turkeltaub PE. 2018. Functional anomaly mapping reveals local and distant dysfunction caused by brain lesions. bioRxiv. 464248.

Dickerson BC, Salat DH, Greve DN, Chua EF, Rand-Giovannetti E, Rentz DM, Bertram L, Mullin K, Tanzi RE, Blacker D, Albert MS, Sperling RA. 2005. Increased hippocampal activation in mild cognitive impairment compared to normal aging and AD. Neurology. 65:404-411.

Efron B, Tibshirani RJ. 1994. An introduction to the bootstrap. 1st ed. Chapman and Hall/CRC.

Ficek BN, Wang Z, Zhao Y, Webster KT, Desmond JE, Hillis AE, Frangakis C, Faria AV, Caffo B, Tsapkini K. 2018. The effect of tDCS on functional connectivity in primary progressive aphasia. Neurolmage Clin.

Fiori V, Coccia M, Marinelli CV, Vecchi V, Bonifazi S, Ceravolo MG, Provinciali L, Tomaiuolo F, Marangolo P. 2011. Transcranial direct current stimulation improves word retrieval in healthy and nonfluent aphasic subjects. J Cogn Neurosci. 23:2309-2323.

Frey S, Campbell JS, Pike GB, Petrides M. 2008. Dissociating the human language pathways with high angular resolution diffusion fiber tractography. J Neurosci Off J Soc Neurosci. 28:11435-11444.

Fridriksson J, Richardson JD, Baker JM, Rorden C. 2011. Transcranial direct current stimulation improves naming reaction time in fluent aphasia: a double-blind, sham-controlled study. Stroke J Cereb Circ. 42:819-821.

Friederici AD. 2009. Pathways to language: fiber tracts in the human brain. Trends Cogn Sci. 13:175181. 
medRxiv preprint doi: https://doi.org/10.1101/2020.07.20.20151043; this version posted July 26, 2020. The copyright holder for this preprint (which was not certified by peer review) is the author/funder, who has granted medRxiv a license to display the preprint in perpetuity. It is made available under a CC-BY-NC-ND 4.0 International license .

Gervits F, Ash S, Diloyan M, Morgan B, Coslett H, Grossman M, Hamilton R. 2015. Transcranial direct current stimulation for the treatment of primary progressive aphasia. Neurology. 84.

Glass GV, McGaw B, Smith ML. 1981. Meta-analysis in social science research. Beverly Hills CA Sage. Gorno-Tempini ML, Hillis AE, Weintraub S, Kertesz A, Mendez M, Cappa SF, Ogar JM, Rohrer JD, Black S, Boeve BF, Manes F, Dronkers NF, Vandenberghe R, Rascovsky K, Patterson K, Miller BL, Knopman DS, Hodges JR, Mesulam MM, Grossman M. 2011. Classification of primary progressive aphasia and its variants. Neurology. 76:1006-1014.

Grodzinsky Y, Amunts K. 2006. Broca's Region. Oxford University Press.

Gruber S, Laan M van der. 2012. tmle: An R Package for Targeted Maximum Likelihood Estimation. J Stat Softw. 51:1-35.

Gurd JM, Amunts K, Weiss PH, Zafiris O, Zilles K, Marshall JC, Fink GR. 2002. Posterior parietal cortex is implicated in continuous switching between verbal fluency tasks: an fMRI study with clinical implications. Brain. 125:1024-1038.

Hickok G, Poeppel D. 2007. The cortical organization of speech processing. Nat Rev Neurosci. 8:393402.

Homan RW. 1988. The 10-20 Electrode System and Cerebral Location. Am J EEG Technol. 28:269_ 279.

Hosseini M, McConathey EM, Ungrady M, Grossman M, Coslett HB, Hamilton RH. 2019. Proceedings \#10: Transcranial Direct Current Stimulation Mediates Improvements in Verbal Fluency for Patients with Primary Progressive Aphasia. Brain Stimul Basic Transl Clin Res Neuromodulation. 12:e69-e71.

Kang EK, Kim YK, Sohn HM, Cohen LG, Paik NJ. 2011. Improved picture naming in aphasia patients treated with cathodal tDCS to inhibit the right Broca's homologue area. Restor Neurol Neurosci. 29:141-152.

Katzev M, Tüscher O, Hennig J, Weiller C, Kaller CP. 2013. Revisiting the Functional Specialization of Left Inferior Frontal Gyrus in Phonological and Semantic Fluency: The Crucial Role of Task Demands and Individual Ability. J Neurosci. 33:7837-7845.

Knopman DS, Kramer JH, Boeve BF, Caselli RJ, Graff-Radford NR, Mendez MF, Miller BL, Mercaldo N. 2008. Development of methodology for conducting clinical trials in frontotemporal lobar degeneration. Brain. 131:2957-2968.

Kroenke K, Spitzer RL, Williams JB. 2001. The PHQ-9: validity of a brief depression severity measure. J Gen Intern Med. 16:606-613.

Kuznetsova A, Brockhoff PB, Christensen RHB. 2017. ImerTest Package: Tests in Linear Mixed Effects Models. J Stat Softw. 82:1-26.

Lazar RM, Minzer B, Antoniello D, Festa JR, Krakauer JW, Marshall RS. 2010. Improvement in aphasia scores after stroke is well predicted by initial severity. Stroke J Cereb Circ. 41:1485-1488.

Lezak M, Loring D, Howieson D. 2004. Neuropsychological Assessment. New York: Oxford University Press.

Libon DJ, McMillan C, Gunawardena D, Powers C, Massimo L, Khan A, Morgan B, Farag C, Richmond L, Weinstein J, Moore P, Coslett HB, Chatterjee A, Aguirre G, Grossman M. 2009. Neurocognitive contributions to verbal fluency deficits in frontotemporal lobar degeneration. Neurology. 73:535-542.

Mandelli ML, Vilaplana E, Brown JA, Hubbard HI, Binney RJ, Attygalle S, Santos-Santos MA, Miller ZA, Pakvasa M, Henry ML. 2016. Healthy brain connectivity predicts atrophy progression in nonfluent variant of primary progressive aphasia. Brain. 139:2778-2791.

Marangolo P, Marinelli CV, Bonifazi S, Fiori V, Ceravolo MG, Provinciali L, Tomaiuolo F. 2011. Electrical stimulation over the left inferior frontal gyrus (IFG) determines long-term effects in the recovery of speech apraxia in three chronic aphasics. Behav Brain Res. 225:498-504.

Margulies DS, Petrides M. 2013. Distinct Parietal and Temporal Connectivity Profiles of Ventrolateral Frontal Areas Involved in Language Production. J Neurosci. 33:16846-16852. 
medRxiv preprint doi: https://doi.org/10.1101/2020.07.20.20151043; this version posted July 26, 2020. The copyright holder for this preprint (which was not certified by peer review) is the author/funder, who has granted medRxiv a license to display the preprint in perpetuity. It is made available under a CC-BY-NC-ND 4.0 International license .

McConathey EM, White NC, Gervits F, Ash S, Coslett H, Grossman M, Hamilton RH. 2017. Baseline performance predicts tdcs-mediated improvements in language symptoms in primary progressive aphasia. Front Hum Neurosci. 11:347.

Meinzer M, Antonenko D, Lindenberg R, Hetzer S, Ulm L, Avirame K, Flaisch T, Floel A. 2012. Electrical brain stimulation improves cognitive performance by modulating functional connectivity and task-specific activation. J Neurosci Off J Soc Neurosci. 32:1859-1866.

Meinzer M, Lindenberg R, Antonenko D, Flaisch T, Flöel A. 2013. Anodal transcranial direct current stimulation temporarily reverses age-associated cognitive decline and functional brain activity changes. J Neurosci. 33:12470-12478.

Meinzer M, Lindenberg R, Sieg MM, Nachtigall L, Ulm L, Flöel A. 2014. Transcranial direct current stimulation of the primary motor cortex improves word-retrieval in older adults. Front Aging Neurosci. 6:253.

Mesulam M. 2008. Primary progressive aphasia pathology. Ann Neurol. 63:124-125.

Mesulam MM. 2001. Primary progressive aphasia. Ann Neurol. 49:425-432.

Mesulam M-M. 2003. Primary Progressive Aphasia - A Language-Based Dementia. N Engl J Med. 349:1535-1542.

Monti A, Cogiamanian F, Marceglia S, Ferrucci R, Mameli F, Mrakic-Sposta S, Vergari M, Zago S, Priori A. 2008. Improved naming after transcranial direct current stimulation in aphasia. J Neurol Neurosurg Psychiatry. 79:451-453.

Mori S, Wu D, Ceritoglu C, Li Y, Kolasny A, Vaillant MA, Faria AV, Oishi K, Miller MI. 2016. MRICloud: Delivering high-throughput MRI neuroinformatics as cloud-based software as a service. Comput Sci Eng. 18:21-35.

Mummery CJ, Patterson K, Wise RJ, Vandenberghe R, Price CJ, Hodges JR. 1999. Disrupted temporal lobe connections in semantic dementia. Brain J Neurol. 122 ( Pt 1):61-73.

Nitsche MA, Paulus W. 2000. Excitability changes induced in the human motor cortex by weak transcranial direct current stimulation. J Physiol. 527 Pt 3:633-639.

Nitsche MA, Paulus W. 2011. Transcranial direct current stimulation - update 2011. Restor Neurol Neurosci.

Penolazzi B, Pastore M, Mondini S. 2013. Electrode montage dependent effects of transcranial direct current stimulation on semantic fluency. Behav Brain Res. 248:129-135.

Petrides M. 1995. Functional organization of the human frontal cortex for mnemonic processing. Evidence from neuroimaging studies. Ann N Y Acad Sci. 769:85-96.

Petrides M. 2006. Broca's area in the human and the non-human primate brain. Broca's Reg. 31-46.

Petrides M. 2014. Neuroanatomy of Language Regions of the Human Brain. New York, NY: Academic Press.

Petrides M, Pandya DN. 2009. Distinct Parietal and Temporal Pathways to the Homologues of Broca's Area in the Monkey. PLOS Biol. 7:e1000170.

Price CJ. 2012. A review and synthesis of the first 20years of PET and fMRI studies of heard speech, spoken language and reading. Neurolmage. 62:816-847.

Race DS, Tsapkini K, Crinion J, Newhart M, Davis C, Gomez Y, Hillis AE, Faria AV. 2013. An area essential for linking word meanings to word forms: evidence from primary progressive aphasia. Brain Lang. 127:167-176.

Rapp B, Glucroft B. 2009. The benefits and protective effects of behavioural treatment for dysgraphia in a case of primary progressive aphasia. Aphasiology. 23:236-265.

Riello M, Faria AV, Ficek B, Webster K, Onyike CU, Desmond J, Frangakis C, Tsapkini K. 2018. The Role of Language Severity and Education in Explaining Performance on Object and Action Naming in Primary Progressive Aphasia. Front Aging Neurosci. 10.

Riello M, Frangakis C, Ficek B, Webster KT, Faria AV, John Desmond, Tsapkini K. n.d. Neural correlates of phonemic and semantic fluency in primary progressive aphasia independent from language and cognitive severity. Rev. 
medRxiv preprint doi: https://doi.org/10.1101/2020.07.20.20151043; this version posted July 26, 2020. The copyright holder for this preprint (which was not certified by peer review) is the author/funder, who has granted medRxiv a license to display the preprint in perpetuity. It is made available under a CC-BY-NC-ND 4.0 International license .

Rofes A, Mandonnet E, de Aguiar V, Rapp B, Tsapkini K, Miceli G. 2018. Language processing from the perspective of electrical stimulation mapping. Cogn Neuropsychol. 1-23.

Rolheiser T, Stamatakis EA, Tyler LK. 2011a. Dynamic processing in the human language system: synergy between the arcuate fascicle and extreme capsule. J Neurosci. 31:16949-16957.

Rolheiser T, Stamatakis EA, Tyler LK. 2011b. Dynamic processing in the human language system: synergy between the arcuate fascicle and extreme capsule. J Neurosci Off J Soc Neurosci. 31:16949-16957.

Roncero C, Kniefel H, Service E, Thiel A, Probst S, Chertkow H. 2017. Inferior parietal transcranial direct current stimulation with training improves cognition in anomic Alzheimer's disease and frontotemporal dementia. Alzheimers Dement Transl Res Clin Interv. 3:247-253.

Rubin D, van der Laan MJ. 2007. A doubly robust censoring unbiased transformation. Int J Biostat. 3:Article 4.

Saur D, Kreher BW, Schnell S, Kümmerer D, Kellmeyer P, Vry M-S, Umarova R, Musso M, Glauche V, Abel S. 2008. Ventral and dorsal pathways for language. Proc Natl Acad Sci. 105:18035-18040.

Saur D, Kreher BW, Schnell S, Kümmerer D, Kellmeyer P, Vry M-S, Umarova R, Musso M, Glauche V, Abel S, Huber W, Rijntjes M, Hennig J, Weiller C. 2008. Ventral and dorsal pathways for language. Proc Natl Acad Sci. 105:18035-18040.

Schlaug G, Marchina S, Wan CY. 2011. The use of non-invasive brain stimulation techniques to facilitate recovery from post-stroke aphasia. Neuropsychol Rev. 21:288-301.

Tang X, Oishi K, Faria AV, Hillis AE, Albert MS, Mori S, Miller MI. 2013. Bayesian Parameter Estimation and Segmentation in the Multi-Atlas Random Orbit Model. PloS One. 8:e65591.

Tao Y, Ficek B, Rapp B, Tsapkini K. n.d. Different patterns of functional network re-organization across the variants of primary progressive aphasia: A graph-theoretic analysis. Rev.

Thompson-Schill SL, Aguirre GK, D’Esposito M, Farah MJ. 1999. A neural basis for category and modality specificity of semantic knowledge. Neuropsychologia. 37:671-676.

Thompson-Schill SL, Bedny M, Goldberg RF. 2005. The frontal lobes and the regulation of mental activity. Curr Opin Neurobiol, Cognitive neuroscience. 15:219-224.

Thompson-Schill SL, D’Esposito M, Aguirre GK, Farah MJ. 1997. Role of left inferior prefrontal cortex in retrieval of semantic knowledge: a reevaluation. Proc Natl Acad Sci. 94:14792-14797.

Tian L, Alizadeh AA, Gentles AJ, Tibshirani R. 2014. A Simple Method for Estimating Interactions between a Treatment and a Large Number of Covariates. J Am Stat Assoc. 109:1517-1532.

Tippett DC, Hillis AE, Tsapkini K. 2015. Treatment of Primary Progressive Aphasia. Curr Treat Options Neurol. 17.

Tombaugh TN. 2004. Trail Making Test A and B: normative data stratified by age and education. Arch Clin Neuropsychol. 19:203-214.

Tsapkini K, Frangakis C, Gomez Y, Davis C, Hillis AE. 2014. Augmentation of spelling therapy with transcranial direct current stimulation in primary progressive aphasia: Preliminary results and challenges. Aphasiology. 28(:1112-1130.

Tsapkini K, Webster KT, Ficek BN, Desmond JE, Onyike CU, Rapp B, Frangakis CE, Hillis AE. 2018. Electrical brain stimulation in different variants of primary progressive aphasia: A randomized clinical trial. Alzheimers Dement Transl Res Clin Interv. 4:461-472.

Tyler LK, Marslen-Wilson WD, Randall B, Wright P, Devereux BJ, Zhuang J, Papoutsi M, Stamatakis EA. 2011a. Left inferior frontal cortex and syntax: function, structure and behaviour in patients with left hemisphere damage. Brain. 134:415-431.

Tyler LK, Marslen-Wilson WD, Randall B, Wright P, Devereux BJ, Zhuang J, Papoutsi M, Stamatakis EA. 2011b. Left inferior frontal cortex and syntax: function, structure and behaviour in patients with left hemisphere damage. Brain J Neurol. 134:415-431.

van der Laan M, Rose S. 2011. Targeted Learning: Prediction and Causal Inference for Observational and Experimental Data. New York: Springer.

Wechsler D. 1981. Manual for the Wechsler adult intelligence scale-revised (WAIS-R). San Antonio TX Psychol Corp. 
medRxiv preprint doi: https://doi.org/10.1101/2020.07.20.20151043; this version posted July 26, 2020. The copyright holder for this preprint (which was not certified by peer review) is the author/funder, who has granted medRxiv a license to display the preprint in perpetuity. It is made available under a CC-BY-NC-ND 4.0 International license.

Zhao Y, Ficek B, Webster K, Wang Z, Desmond JE, Hillis AE, Frangakis CE, Caffo B, Faria A, Tsapkini K. under review. Transcranial direct current stimulation: integrity of white-matter tracts moderates effects in primary progressive aphasia. 